\title{
Comment on "Systematic Review: Isocaloric Ketogenic Dietary Regimes for Cancer Patients” by Erickson et al
}

\author{
Csaba Tóth ${ }^{1}$, Andrea Dabóczi ${ }^{1}$, Madhvi Chanrai ${ }^{2}$, Zsófia Clemenss ${ }^{1, *}$ \\ ${ }^{1}$ Paleomedicina Hungary Ltd, Evolutionary Medicine Working Group, Budapest, Hungary \\ ${ }^{2}$ Independent Researcher \\ *Corresponding author: clemenszsofia@gmail.com
}

Cite This Article: Csaba Tóth, Andrea Dabóczi, Madhvi Chanrai, and Zsófia Clemens, "Comment on "Systematic Review: Isocaloric Ketogenic Dietary Regimes for Cancer Patients" by Erickson et al." Journal of Cancer Research and Treatment, vol. 5, no. 3 (2017): 86-88. doi: 10.12691/jcrt-5-3-2.

Erickson et al. [1] recently published a review on the use of the ketogenic diet in cancer. The authors of this reply are clinicians who bring into play an evolutionary approach in the practice of medicine and specifically have been using the paleolithic ketogenic diet in the treatment of chronic diseases since 2011 [2-9]. We have instituted the paleolithic ketogenic diet in approximately 4000 patients, of whom several hundred have been followed up for at least one year, and 60 cancer patients who have been followed up for at least 6 months. Previously (prior to 2011) we had been using the classic paleolithic diet, which was useful in the treatment of certain diseases but proved to be ineffective in the treatment of autoimmune diseases and cancer.

Moving forward from the paleolithic diet we developed the paleolithic ketogenic diet, which is an animal meat-fat based diet similar to that originally proposed by Voegtlin [10], and fine-tuned it through clinical feedback (laboratory work-up, imaging and symptomatology).

During the past few decades experimental research has led to the emergence of the ketogenic diet as a potential cancer treatment. Much of this research has been carried out by Professor Thomas Seyfried who has also proposed a unifying theory on the origin of cancer and its potential cure [11]. Unfortunately, his significant contribution to this subject has not been included in the Erickson et al. review.

The review also contains inaccuracies and factual errors, as also pointed out by Klement et al. [12] and Gonder [13]. Overall, the review can be regarded as a reflection of the flawed approach frequently seen in the mainstream medical literature as well as in the guidelines. Recently, however, several of these established credos have been challenged, including the alleged relationship between cancer and red meat consumption [14] as well as the actual effectiveness of expensive cancer drugs [15]. Against this background, it is not unreasonable for cancer patients to seek alternative options for the management of their condition.

Although we strongly agree with most of the criticisms by Klement et al. [12] and Gonder [13], we do also agree with one point in the review which is that clinical ketogenic trials so far have provided next to no or very little evidence that the ketogenic diet is effective in terms of survival benefit.
Although the review by Erickson et al. correctly listed several cancer-related ketogenic studies, they did not include our recent case study [9] reporting on halted progression of an aggressive soft palate tumor for 20 months whilst adhering to the paleolithic ketogenic diet. Currently that patient is still progression-free, side-effect-free and has had an excellent quality of life for the last 28 months. Importantly, during the entire course of her disease she did not receive any other anti-cancer treatment, nor was she on any other medication or dietary supplements. As far as we can see this is the most successful cancer case in the published literature in terms of minimizing side-effects whilst also achieving substantial survival gain.

Yet she is not the only cancer patient benefiting from the paleolithic ketogenic diet. Below we provide a table summarizing the data of some of our most successful cancer patients.

We would also like to add that none of our patients experienced any side effects attributable to the paleolithic ketogenic diet. It may surprize many, even those from the ketogenic diet field, that the paleolithic ketogenic diet does not predispose to vitamin C deficiency [16].

At the same time we would like to point out that side effects of the classical version of the ketogenic diet do exist, as listed by Erickson et al., even though they are easier to reverse compared with the side-effects of radiotherapy and chemotherapy. In our experience the side-effects of the standard cancer therapies are often not reversed, and these standard treatments also hinder recovery when using the paleolithic ketogenic diet.

We have also noticed that the side-effects of the classical ketogenic diet are exactly the same as the "side-effects" of the "standard" Western-type diet. It is intriguing, however, that when they occur on the Western-type diet they are not referred to as side-effects but mainly of unkown or genetic origin. To be strictly accurate, there are no studies (not even from the pediatric epilepsy literature) comparing the prevelance of side effects between the ketogenic and Western-type diets. Also, no studies are available that control for the effect of the antiepileptic or other medication whilst on the ketogenic diet, so the side-effects of medication and those of the ketogenic diet cannot be discerned. 
Table 1. Long-term progression-free cancer patients in our practice. Note that these patients used the diet as a stand-alone therapy and did not receive chemotherapy/radiation treatment (except for pat \#3 who received radiotherapy in the initial 1.5-months period of diet therapy.)

\begin{tabular}{|c|c|c|c|c|c|c|c|}
\hline & $\begin{array}{l}\text { Cancer } \\
\text { type }\end{array}$ & Histopathology & $\begin{array}{l}\text { Age at diet } \\
\text { onset (years) }\end{array}$ & $\begin{array}{l}\text { Follow-up } \\
\text { (months) }\end{array}$ & $\begin{array}{l}\text { Disease course } \\
\text { while on the diet }\end{array}$ & Standard therapy & \\
\hline Patient \#1 & Colon & Adenocarcinoma & 56 & 37 & No recurrence & $\begin{array}{l}\text { Before the diet } \\
\text { Surgery }\end{array}$ & $\begin{array}{l}\text { While on the diet } \\
\text { No }\end{array}$ \\
\hline Patient \#2 & $\begin{array}{l}\text { Soft } \\
\text { palate }\end{array}$ & Myoepithelial & 60 & 28 & Stable & No & No \\
\hline Patient \#3 & Rectal & Adenocarcinoma & 62 & 24 & Stable & No & $\begin{array}{l}\text { RT only for } 1.5 \\
\text { months }\end{array}$ \\
\hline Patient \#4* & Colon & $\begin{array}{l}\text { Adenocarcinoma } \\
\text { grade 4, inoperable }\end{array}$ & 72 & 21 & $\begin{array}{l}\text { Tumor turned } \\
\text { operable, later } \\
\text { complete remission }\end{array}$ & No & Surgery \\
\hline Patient \#5 & CIN & CIN III, recurrent & 46 & 19 & $\begin{array}{l}\text { Complete } \\
\text { normalization }\end{array}$ & $\begin{array}{l}\text { Fr. cu., then } \\
\text { positive cytology }\end{array}$ & No \\
\hline Patient \#6 & $\begin{array}{l}\text { Brain } \\
\text { Bladder }\end{array}$ & Glioblastoma & 53 & 8 & Stable & $\begin{array}{l}\text { Surgery, RCT } \\
\text { followed by } \\
\text { progression }\end{array}$ & No \\
\hline
\end{tabular}

Abbreviations: CIN: cervical intraepithelial neoplasia; * died due to cause unrelated to the original disease; Fr. cu.: fractioned curettage, RT: radiotherapy; RCT: radio/chemotherapy.

We believe that the side effects of the classical ketogenic diet and that of the Western-type diet are due to a massive divergence from the meat-fat based diet, the only diet that we are evolutionarily adapted to. The lack of specific food components (such as animal fats and offal) as well as the presence/surplus of non-evolutionary adapted food components (e.g. cereal grains, milk, dairy, vegetable oils and additives) may trigger pathological conditions $[17,18]$.

Food components to which we are non-evolutionarily adapted (e.g. certain compounds found in vegetables) may result in pathological permeability of the intestines which may be accompanied by increased permeability of other membranes (e.g. the blood-brain barrier) as well as compromized cell junctions and contact inhibition within various tissues $[19,20]$. It has been suggested that these phenomena share common physiological components and all have been implicated in the promotion of tumorigenesis. By excluding these food components, the paleolithic ketogenic diet may counteract tumorigenesis through the normalization of intestinal permeability, as we have shown in a Crohn's patient [8], and possibly also through the normalization of cell-to-cell communication within the cancerous tissue as suggested by the fact that follow up histology in some of our cases has shown normalization of cancerous tissue.

Unlike the approach of Erickson et al. we view ketosis as a physiological rather than a pathological condition. It follows on from this that the negative effects of the classical ketogenic diet do not result from the ketosis itself but, as detailed above, emerge from the unhealthy and evolutionarily maladapted composition of these diets. Despite their current popularity, coconut oil, olive oil and other vegetable oils labeled as "healthy" have never been part of our evolutionary diet. The same holds true for flavored yoghurt drinks, sour cream and ketogenic diet formulas (typical components of the ketogenic diets in the published papers). Ketosis as an evolutionarily adapted condition is generally ackowledged among ketogenic diet practicioners. But why not adapt the ketogenic diet in a way that humans were subsisting on for 2.6 million years?

Once one accepts that humans are meat-eaters by nature $[10,21]$, several apparent conflicts seem to resolve. In our practice we clearly see the principles and insights of Professor Seyfried derived from animal models manifest in many respects. For example, as predicted by Seyfried et al. [22], we see that radio/chemotherapy counteracts the effect of the paleolithic ketogenic diet. Patients using the paleolithic ketogenic diet as an adjunct to standard radio/chemotherapy benefit much less from the diet as compared to those using the diet as a stand-alone therapy. In fact, as is clear from the table, patients with the longest progression-free survival did not use radio/chemotherapy.

Concurrent standard therapy might have contributed to the overall lack of clinical success of previous trials with the classical ketogenic diet too, given that all previous ketogenic diet trials used the diet as an adjunct to (or following the failed trials of) standard therapies.

Although there are four versions of the low carb/high fat diet, as correctly mentioned by Erickson et al., these four versions do not substantially differ in the food components they contain. The ketogenic diets in the published studies derive fat mainly from vegetable sources, a likely reflection of a longstanding fear of animal fat. Importantly, mice and rats as omnivorous animals may respond to a plant-based ketogenic diet more favorably as compared to humans who are meat-eaters by biology, a factor that may explain why the classical ketogenic diet seems to be effective in rodents but ineffective in humans. For this reason, it might be more expedient to use a carnivorous animal for modeling human ketosis instead of rodents.

In the clinicaltrials.gov database there are nine ketogenic-cancer trials registered as recruiting, three as not yet recruiting and three others labeled as terminated due to poor accrual. As already mentioned, finalized ketogenic trials did not reveal any meaningful benefit in survival. To us it appears that an erroneous ketogenic diet is being used again and again.

Instead of this ineffectual approach we would recommend being guided by positive clinical experience, even if it is from case studies, small-scale reports or a practitioner's own experience, as in the era before modern clinical studies.

Being able to see the different versions of the ketogenic diet clearly, including their possible risks and benefits, is very important for health practicioners in the field of oncology. In our experience, oncologists who are against the ketogenic diets (due to both justified and unjustified reasons), frequently put pressure on cancer patients to accept standard treatments; try to dissuade patients from 
following the diet; or force patients to chose between diet and oncological follow-up, thereby putting patients in a dilemna.

A closing comment on why so few ketogenic diet studies are available: it is extremely difficult to publish clinical data from the ketogenic diet in a reputable medical journal because it represents a major deviation from the standard point of view. Our personal experience is that publishing positive results (not to mention full recovery of a cancer patient) due to a diet is virtually impossible.

\section{Competing Interests}

No competing interests were disclosed.

\section{Grant Information}

The authors declared that no grants were involved in supporting this work.

\section{Informed Consent}

Informed consent was obtained from all individual participants whose data were included in the comment.

\section{References}

[1] Erickson N, Boscheri A, Linke B, Huebner J. Systematic review: isocaloric ketogenic dietary regimes for cancer patients. Med Oncol. 2017; 34: 72.

[2] Clemens Z, Kelemen A, Fogarasi A, Tóth C. Childhood absence epilepsy successfully treated with the paleolithic ketogenic diet. Neurol Ther. 2013; 2: 71-6.

[3] Tóth C, Clemens Z. Type 1 diabetes mellitus successfully managed with the paleolithic ketogenic diet. Int $\mathrm{J}$ Case Rep Images. 2014; 5: 699-703.

[4] Clemens Z, Kelemen A, Tóth C. NREM-sleep Associated Epileptiform Discharges Disappeared Following a Shift toward the Paleolithic Ketogenic Diet in a Child with Extensive Cortical Malformation. Am J Med Case Rep. 2015; 3: 212-215.

[5] Tóth C, Clemens Z. A child with type 1 diabetes mellitus (T1DM) successfully treated with the Paleolithic ketogenic diet: A 19-month insulin freedom. Int $\mathrm{J}$ Case Rep Images. 2015; 6: 752-757.

[6] Tóth C, Clemens Z. Successful treatment of a patient with obesity, type 2 diabetes and hypertension with the paleolithic ketogenic diet. Int J Case Rep Images. 2015; 6: 161-167.

[7] Tóth C, Clemens. Gilbert's syndrome successfully treated with the paleolithic ketogenic diet. Am J Med Case Rep. 2015; 3: 117-120.

[8] Tóth C, Dabóczi A, Howard M, Miller NJ, Clemens Z. Crohn’s disease successfully treated with the paleolithic ketogenic diet. Int J Case Rep Images. 2016; 7: 570-578.

[9] Tóth C, Clemens Z. Halted progression of soft palate cancer in a patient treated with the paleolithic ketogenic diet alone: A 20months Follow-up. Am J Med Case Rep. 2016; 4: 288-292.

[10] Voegtlin WL. The stone age diet: based on in-depth studies of human ecology and the diet of man. New York: Vantage Press, 1975.

[11] Seyfried TN. Cancer as a Metabolic Disease: On the Origin, Management, and Prevention of Cancer. Hoboken, New Jersey, Wiley, 2012.

[12] Klement RJ, Feinman RD, Gross EC, Champ CE, D’Agostino DP Fine EJ, Kämmerer U, Poff A, Rho JM, Seyfried TN, Scheck AC. Need for new review of article on ketogenic dietary regimes for cancer patients. Med Oncol. 2017; 34: 108.

[13] Gonder U. Article on ketogenic dietary regimes for cancer highly misleading. Med Oncol. 2017; 34: 109

[14] Alexander DD, Cushing CA. Red meat and colorectal cancer: a critical summary of prospective epidemiologic studies. Obes Rev. 2011; 12: e472-93.

[15] Aggarwal A, Fojo T, Chamberlain C, Davis C, Sullivan R. Do patient access schemes for high-cost cancer drugs deliver value to society?-lessons from the NHS Cancer Drugs Fund. Ann Oncol 2017 Apr 27.

[16] Clemens Z, Tóth C. Vitamin C and Disease: Insights from the Evolutionary Perspective. J Evol Health. 2016; 1: Article 13.

[17] Cordain L. The paleo diet: lose weight and get healthy by eating the food you were designed to eat. New York, Wiley, 2002.

[18] Lindeberg S. Food and western disease: health and nutrition from an evolutionary perspective. Wiley-Blackwell, 2009.

[19] Kominsky SL, Argani P, Korz D, Evron E, Raman V, Garrett E, Rein A, Sauter G, Kallioniemi OP, Sukumar S. Loss of the tight junction protein claudin-7 correlates with histological grade in both ductal carcinoma in situ and invasive ductal carcinoma of the breast. Oncogene. 2003; 22: 2021-33.

[20] Lin JE, Snook AE, Li P et al. GUCY2C Opposes Systemic Genotoxic Tumorigenesis by Regulating AKT-Dependent Intestinal Barrier Integrity. PLoS ONE 2012;7:2,e31686

[21] Bocherens H, Fizet M, Mariotti A, Lange-Badre B, Vandermeersch B Borel JP, Bellon G, Isotopic biogeochemistry $(13 \mathrm{C}, 15 \mathrm{~N})$ of fossil vertebrate collagen: application to the study of a past food web including Neandertal man. J Hum Evol. 1991; 20, 481-492.

[22] Seyfried TN, Shelton LM, Mukherjee P. Does the existing standard of care increase glioblastoma energy metabolism? Lancet Oncol. 2010; 11: 811-3. 